\title{
Streptococcal Toxic Shock Syndrome after Thyroid Lobectomy: Case Report and Literature Review
}

\author{
Patricia Tejedor Togores, Joaquín Gómez-Ramírez, Irene Osorio Silla, Carlos Pastor, Irene López Rojo, \\ Sonia Rivas Fidalgo, and Mariano Díaz Miguel
}

\begin{abstract}
Background: Group A streptococcal (GAS) infection after thyroid surgery is a rare occurrence. Its incidence has not been described in the literature.

Methods: This report presents an overview of streptococcal toxic shock syndrome in order to improve the management of the condition and the patient outcome.

Results: A case of GAS toxis shock syndrome secondary to a inadvertent tracheal perforation during a thyroidectomy is presented.

Conclusion: Rapid and thorough diagnosis is essential and all surgeons must have a high index of suspicion for this rare but concerning disease.
\end{abstract}

T HE OVERALL COMPLICATION RATE after thyroid surgery is less than $5 \%$, which is primarily associated with airway complications in big goiters. A recent publication showed that mortality after thyroidectomy is $0.06 \%$, and only $10 \%$ is caused by sepsis [1].

Thyroid surgery is considered a clean procedure. The incidence of surgical site infection (SSI) following a thyroidectomy is less than 3\% [2-4], therefore antibiotic prophylaxis is not recommended according to international guidelines [5]. The global incidence of SSI caused by group A streptococcal (GAS) is $8.3 \%$ [6] and the overall fatality rate after the infection is $13 \%$ [7]. Symptoms and signs are similar to any other SSI: Flu-like symptoms, confusion, erythema and induration, suppuration, and pain and fever.

\section{Case Presentation}

A 44-year-old female with no past medical history was referred to the division of endocrine surgery for examination of a unique thyroid nodule of $10 \mathrm{~mm}$ in diameter on the right lobe, diagnosed by ultrasound (US). Fine needle aspiration guided by US was performed and the cytological examination revealed a suspicious Hürthle cell neoplasm
(Bethesda IV). The patient underwent a right thyroid lobectomy and isthmectomy. No pre-operative prophylactic antibiotics were administered. The surgery followed the aseptic technique and the patient did not receive corticosteroids intra-operatively. Drains were not used and the patient was discharged on post-operative day 1 without any complications.

On post-operative day 2 the patient came to the emergency department with fever $\left(38.5^{\circ} \mathrm{C}\right)$ dysphagia, dysphonia, and dyspnoea. Computed tomography (CT) was normal but she presented systemic inflammatory response syndrome secondary to sepsis. She was taken to the operating room (OR) urgently to perform a debridement by a cervical incision, which drained cloudy liquid. There was no extension into the mediastinum and initially there was no evidence of tracheoesophageal injury. A penrose drain was placed. The patient was admitted to the intensive care unit (ICU) with respiratory distress requiring respiratory and nutritional support (Fig. 1). The microbiology report diagnosed a GAS infection based on positive blood cultures, thus the patient received antibiotic coverage with penicillin G. On post-operative day 10 , an air leak was observed at the surgical site. The investigation of the leak was

Department of General Surgery, Division of Endocrine Surgery, University Hospital Fundación Jiménez Díaz, Madrid, Spain.

(C) Patricia Tejedor Togores et al. 2016; Published by Mary Ann Liebert, Inc. This Open Access article is distributed under the terms of the Creative Commons License (http://creativecommons.org/licenses/by/4.0), which permits unrestricted use, distribution, and reproduction in any medium, provided the original work is properly credited. 


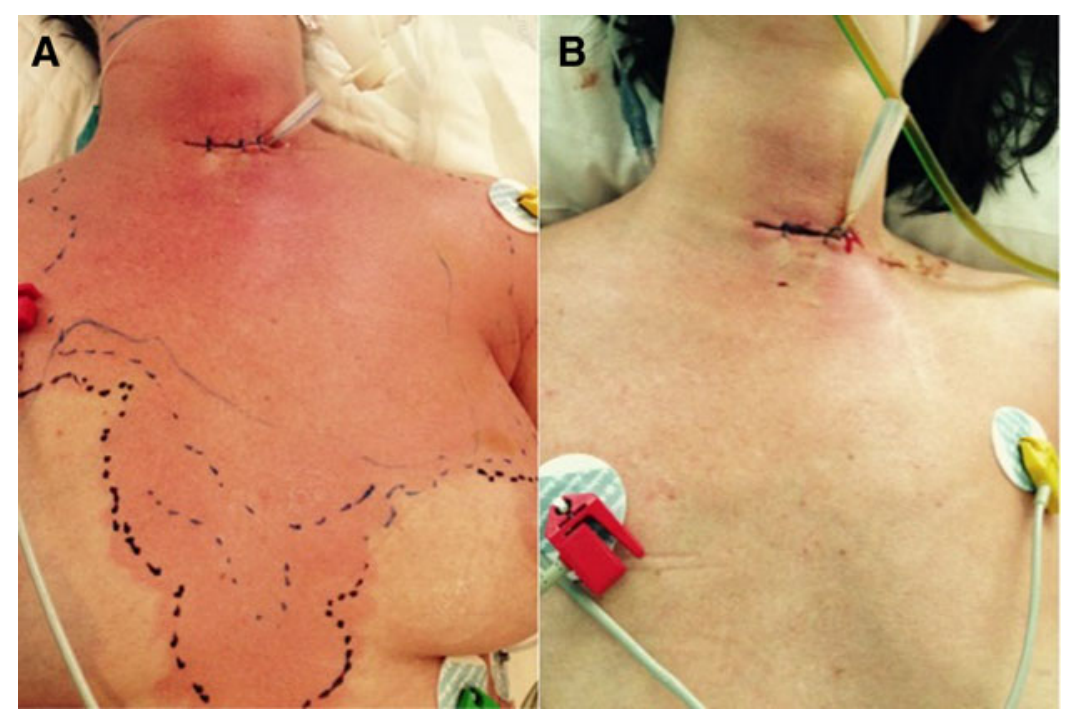

FIG. 1. Regional erythema evolution. (A) Day 1 ICU; (B) Day 4 ICU.

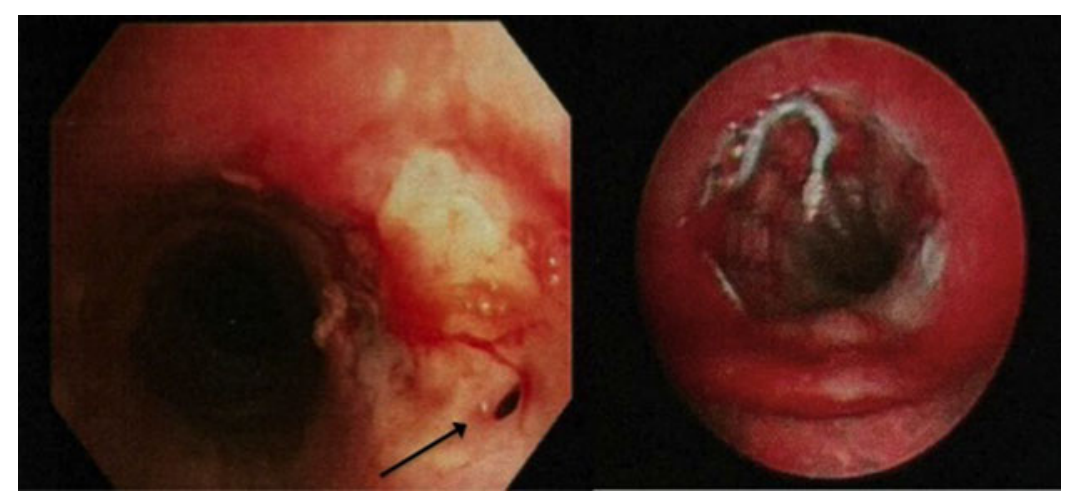

FIG. 2. Bronchoscopy. A) Tracheal fistula; B) Temporary prosthesis.

completed by bronchoscopy showing a tracheal fistula of $4 \mathrm{~mm}, 2 \mathrm{~cm}$ above the vocal cords. A temporary prosthesis was placed (Fig. 2) and recovery was uneventful until discharge (post-operative day 13) (Fig. 3). The endotracheal prosthesis was withdrawn 1 wk later. After 2 mo of

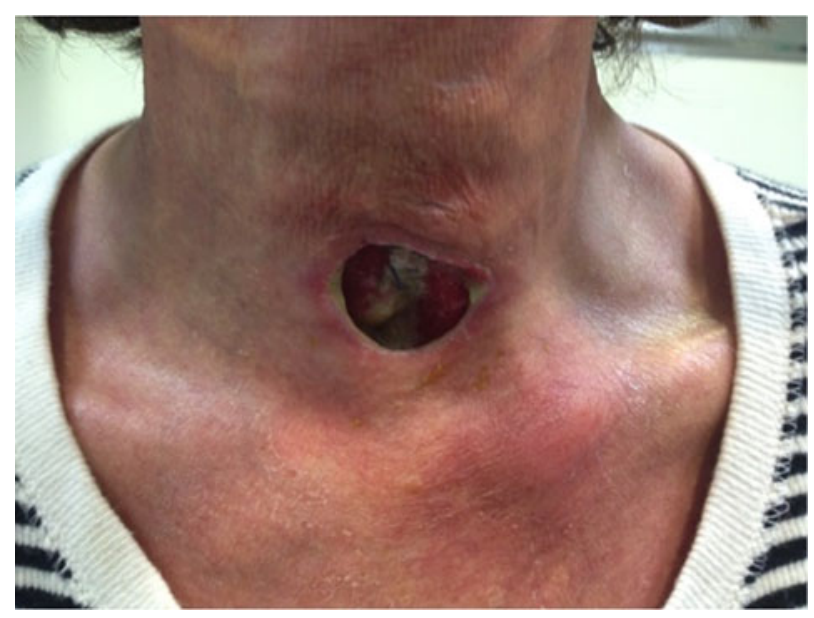

FIG. 3. Day before patient discharge. follow-up, a new bronchoscopy was performed, which showed complete healing of the fistula track (Fig. 4) and the surgical site (Fig. 5).

\section{Discussion}

We present a rare case of GAS toxic shock syndrome secondary to an inadvertent tracheal perforation during a thyroidectomy.

A GAS toxic shock syndrome one or two days after clean surgery is a rare occurrence. Cone et al. [8] was the first group to describe GAS toxic shock syndrome in the 1980s. It was defined as the presence of hypotension plus two of the following: Respiratory distress syndrome, renal failure, coagulation abnormalities, and hepatic dysfunction [9]. Its incidence and mortality has not been described in the literature. To date, there are only 11 cases of GAS infection after thyroidectomy reported in the literature (Table 1) [1, 10-15], and many of these cases were complicated by septic shock and death despite early systemic antibiotic treatment. However, there are no cases with GAS infection secondary to tracheal perforation, as we present here. In addition, the reported incidence of tracheal perforation is as low as $0.06 \%$ in an extensive review of more than 11,000 thyroidectomies [16]. 
Table 1. Review of Patients with GAS Infection after Thyroidectomy

\begin{tabular}{|c|c|c|c|c|c|c|c|}
\hline $\begin{array}{l}\text { Case } \\
\text { no. }\end{array}$ & Author & $\begin{array}{l}\text { Year, } \\
\text { country }\end{array}$ & $\begin{array}{c}\text { Age (y), } \\
\text { gender }\end{array}$ & $\begin{array}{l}\text { Post-operative } \\
\text { day }\end{array}$ & $\begin{array}{l}\text { Toxic shock } \\
\text { syndrome }\end{array}$ & $\begin{array}{l}\text { Tracheal } \\
\text { injury }\end{array}$ & Outcome \\
\hline 1 & $\mathrm{CDC}$ & 1996, US & 28, Female & 1 & Yes & No & Death \\
\hline 2 & $\mathrm{CDC}$ & 1996, US & 56, Female & 1 & Yes & & Death \\
\hline 3 & CDC & 1996, US & 57, Female & 2 & Yes & No & Survival \\
\hline 4 & Szczypa & 2001, Poland & 55, Male & 2 & Yes & & Death \\
\hline 5 & Faibis & 2001, France & 61, Female & 2 & No & No & Survival \\
\hline 6 & Faibis & 2003, France & 58 , Female & 2 & Yes & No & Death \\
\hline 7 & Faibis & 2004, France & 36, Female & 2 & Yes & No & Death \\
\hline 8 & Hardy & 2007, UK & 38 , Female & 1 & Yes & No & Death \\
\hline 9 & Nikolaos & 2007, Greece & 47, Female & 2 & Yes & No & Survival \\
\hline 10 & Karlik & 2013, US & 47, Male & 2 & Yes & No & Survival \\
\hline 11 & Gómez-Ramírez & 2015, Spain & 37, Female & 2 & Yes & - & Death \\
\hline
\end{tabular}

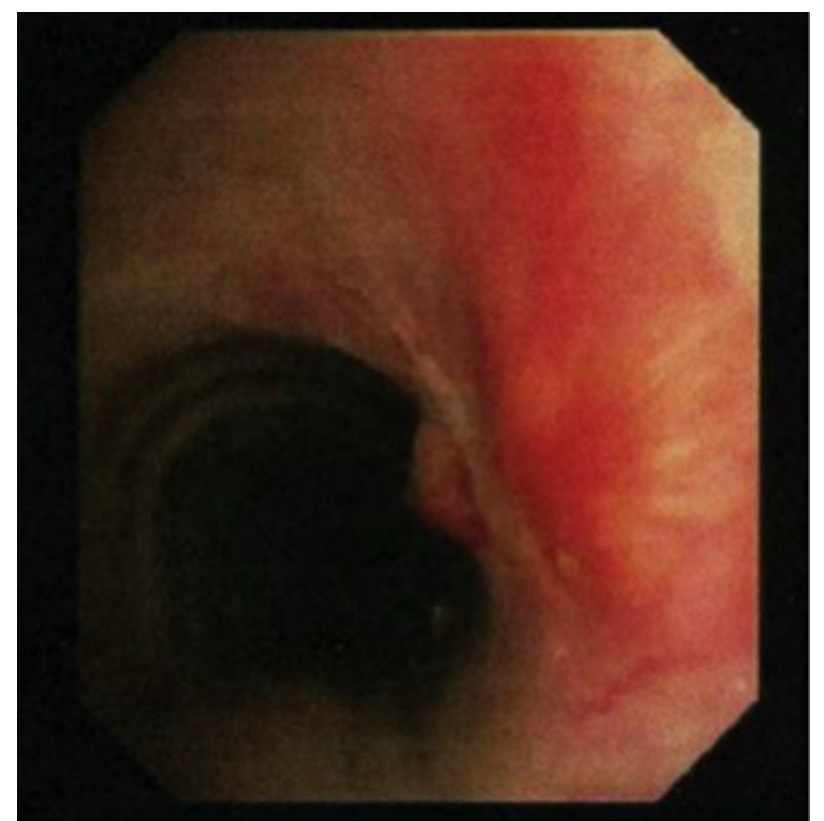

FIG. 4. Bronchoscopy after 2 mo. Healing of the fistula track.

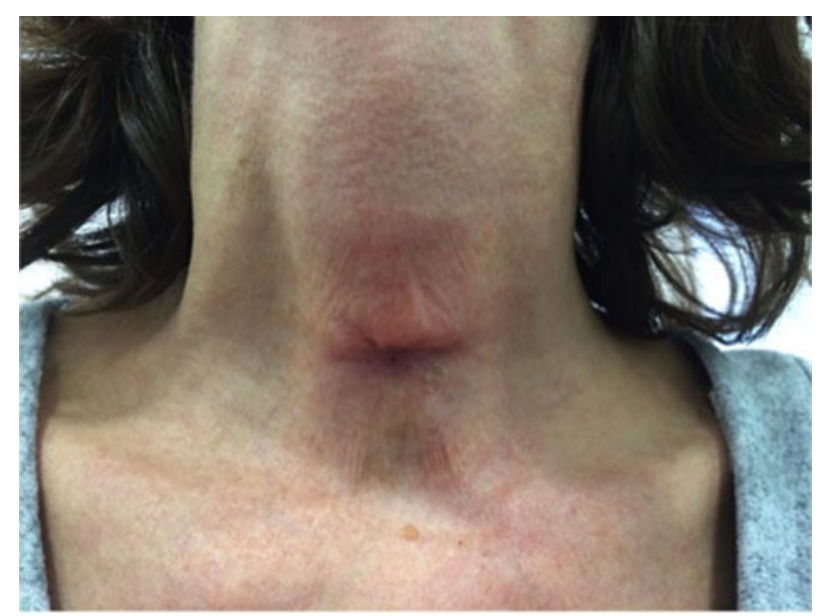

FIG. 5. Surgical cite after 2 mo.
GAS colonization could be detected before surgery, but routine testing is not usually performed. If there is suspicion of a severe neck infection after thyroid surgery, a CT should be performed to reveal the existence and the extent of the infection. There are only two cases reported in the literature of necrotizing mediastinitis because of the descending of GAS SSI [13, 17], but this is a possible complication. The definitive diagnosis of GAS infection is based on positive blood cultures but only $60 \%$ of patients have bateriemia [7]. However, any suspicion of GAS infection should be treated with high doses of penicillin and debridement. Follow-up CT is important also after first debridement because in some cases an additional operation is required.

\section{Conclusions}

The detection of the first signs of post-operative complications and identification of a GAS infection is crucial in order to prevent a fatal outcome. Inadvertent tracheal perforation should also be avoided by all surgeons after thyroidectomies because of a high association with GAS infection.

\section{Acknowledgments}

The authors thank Mr. V. Matilla for editing this manuscript.

\section{Author Disclosure Statement}

The authors declare that they have no competing interests.

\section{References}

1. Gomez-Ramirez J, Sitges-Serra A, Moreno-Llorente P, et al. Mortality after thyroid surgery, insignificant or still an issue? Langenbeck's Arch Surg/Deutsche Gesellschaft fur Chirurgie 2015;400:517-522.

2. Rosato L, Avenia N, Bernante P, et al. Complications of thyroid surgery: Analysis of a multicentric study on 14,934 patients operated on in Italy over 5 years. World J Surg 2004;28:271-276.

3. Dionigi G, Rovera F, Boni L, et al. Surveillance of surgical site infections after thyroidectomy in a one-day surgery setting. Int J Surg 2008;6:S13-S15.

4. Dionigi G, Rovera F, Boni L, et al. Surgical site infections after thyroidectomy. Surg Infect 2006;7:S117-S120. 
5. Directors ABo. Recommended practices for skin preparation of patients. AORN J 2002;75:184-187.

6. Daneman N, McGeer A, Low DE, et al. Hospital-acquired invasive group a streptococcal infections in Ontario, Canada, 1992-2000. Clin Infect Dis 2005;41:334-342.

7. Sharkawy A, Low DE, Saginur R, et al. Severe group a streptococcal soft-tissue infections in Ontario: 1992-1996. Clin Infect Dis 2002;34:454-460.

8. Cone LA, Woodard DR, Schlievert PM, et al. Clinical and bacteriologic observations of a toxic shock-like syndrome due to Streptococcus pyogenes. NEJM 1987;317:146-49.

9. Infections WGoSS. Defining the group A streptococcal toxic shock syndrome: Rationale and consensus definition. JAMA 1993;269:390-391.

10. Faibis F, Sapir D, Luis D, et al. Severe group a streptococcus infection after thyroidectomy: Report of three cases and review. Surg Infect 2008;9:529-531.

11. Karlik JB, Duron V, Mermel LA, et al. Severe group a streptococcus surgical site infection after thyroid lobectomy. Surg Infect 2013;14:216-220.

12. Szczypa K, Sadowy E, Izdebski R, et al. Group A streptococci from invasive-disease episodes in Poland are remarkably divergent at the molecular level. J Clin Microbiol 2006;44:3975-3979.

13. Nikolaos ND, Apostolakis EE, Marangos MN, et al. A less invasive management of post-thyroidectomy descending necrotizing mediastinitis is feasible: A case report and literature review. Med Sci Monit 2007;13:Cs83-Cs87.

14. Hardy RG and Forsythe JL. Uncovering a rare but critical complication following thyroid surgery: An audit across the UK and Ireland. Thy 2007;17:63-65.

15. US Centers for Disease Control and Prevention. Nosocomial group A streptococcal infections associated with asymp- tomatic health-care workers-Maryland and California, 1997. JAMA 1999;281:1077-1078.

16. Gosnell JE, Campbell P, Sidhu S, et al. Inadvertent tracheal perforation during thyroidectomy. Brit J Surg 2006;93: 55-56.

17. Menegaux F, Leenhardt L, Dahman M, et al. Repeated thyroid surgery. Indications and results. Presse medicale 1997;26:1850-1854.

Address correspondence to: Dr. Patricia Tejedor Togores Avenida Reyes Católicos \#2 28040 Madrid, Spain

E-mail: patricia.tejedor@hotmail.com

$$
\begin{aligned}
& \text { Abbreviations Used } \\
& \text { CT }=\text { computed tomography } \\
& \text { GAS }=\text { group A streptococcal } \\
& \text { ICU }=\text { intensive care unit } \\
& \text { US }=\text { ultrasound }
\end{aligned}
$$

Cite this article as: Tejedor Togores $\mathrm{P}$, Gómez-Ramírez J, Osorio Silla I, Pastor C, López Rojo I, Rivas Fidalgo S, and Díaz M (2016) Streptococcal toxic shock syndrome after thyroid lobectomy: Case report and literature review, Surgical Infections Case Reports 1:1, 22-25, DOI: $10.1089 / \mathrm{crsi} .2016 .0001$. 